\title{
Maternal Super Obesity and Neonatal Morbidity after Term Cesarean Delivery
}

\author{
Marcela C. Smid, MD, MA, MS ${ }^{1} \quad$ Catherine J. Vladutiu, PhD, MPH ${ }^{1} \quad$ Sarah K. Dotters-Katz, MD \\ Tracy A. Manuck, MD, MSCl ${ }^{1}$ Kim A. Boggess, MD ${ }^{1}$ David M. Stamilio, MD, MSCE ${ }^{1}$ \\ ${ }^{1}$ Division of Maternal Fetal Medicine, Department of Obstetrics \& \\ Gynecology, University of North Carolina, Chapel Hill, North Carolina \\ Address for correspondence Marcela C. Smid, MD, MA, MS, Division of \\ Maternal Fetal Medicine, Department of Obstetrics \& Gynecology, \\ University of North Carolina, 3010 Old Clinic Building CB\# 7516, \\ Am J Perinatol 2016;33:1198-1204. \\ Chapel Hill, NC 27599 (e-mail: Marcela.Smid@hsc.utah.edu).
}

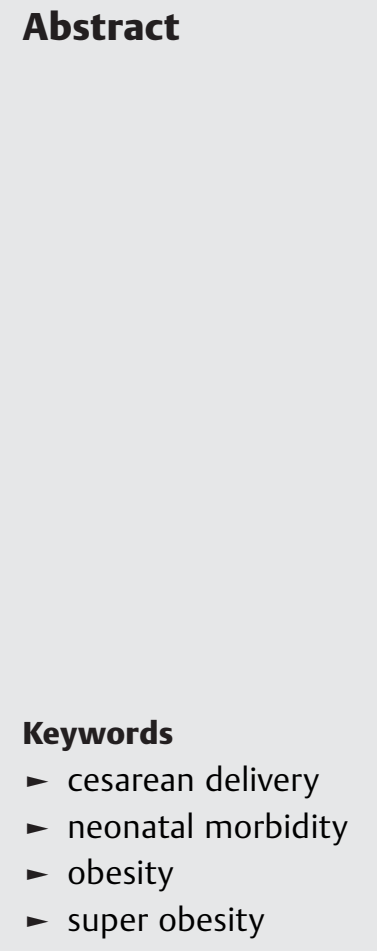

Objective To estimate the association between maternal super obesity (body mass index $[\mathrm{BMI}] \geq 50 \mathrm{~kg} / \mathrm{m}^{2}$ ) and neonatal morbidity among neonates born via cesarean delivery (CD).

Methods Retrospective cohort of singleton neonates delivered via $C D \geq 37$ weeks in the Maternal-Fetal Medicine Unit Cesarean Registry. Maternal BMI at delivery was stratified as 18.5 to $29.9 \mathrm{~kg} / \mathrm{m}^{2}, 30$ to $39.9 \mathrm{~kg} / \mathrm{m}^{2}, 40$ to $49.9 \mathrm{~kg} / \mathrm{m}^{2}$, and $\geq 50 \mathrm{~kg} / \mathrm{m}^{2}$. Primary outcomes included acute (5-minute Apgar score $<5$, cardiopulmonary resuscitation and ventilator support $<24$ hours, neonatal injury, and/or transient tachypnea of the newborn) and severe (grade 3 or 4 intraventricular hemorrhage, necrotizing enterocolitis, seizure, respiratory distress syndrome, hypoxic ischemic encephalopathy, meconium aspiration, ventilator support $\geq 2$ days, sepsis and/or neonatal death) neonatal morbidity. Odds of neonatal morbidity were estimated for each BMI category adjusting for clinical and operative characteristics.

Results Of 41,262 maternal-neonatal dyads, $36 \%$ of women were nonobese, $49 \%$ had BMI of 30 to $39.9 \mathrm{~kg} / \mathrm{m}^{2}, 12 \%$ had BMI of 40 to $49.9 \mathrm{~kg} / \mathrm{m}^{2}$, and $3 \%$ were super obese. Compared with nonobese women, super obese women had twofold odds of acute ( 5 vs. $10 \%$; adjusted odds ratio [aOR]: $1.81,95 \%$ confidence interval $[\mathrm{Cl}]: 1.59-2.73)$ and severe (3 vs. $6 \%$; aOR: 2.08 ; $95 \% \mathrm{Cl}: 1.59-2.73$ ) neonatal morbidity.

Conclusion Among term infants delivered via $\mathrm{CD}$, maternal super obesity is associated with increased risk of neonatal morbidity.
Maternal obesity in the United States has reached epidemic proportions, and super obesity, defined as body mass index (BMI) $\geq 50 \mathrm{~kg} / \mathrm{m}^{2}$, is the fastest growing obesity group in the United States. ${ }^{1}$ Maternal obesity is a well-recognized independent risk factor for cesarean delivery (CD). ${ }^{2-4}$ Class III obese (BMI $\geq 40 \mathrm{~kg} / \mathrm{m}^{2}$ ) nulliparous women are three to four times more likely to undergo $\mathrm{CD}$ compared to normal weight women, ${ }^{3,5}$ and more than half of multiparous women with class III obesity attempting a vaginal birth after cesarean (VBAC) deliver via repeat $C D .{ }^{6}$ Among super obese women, approximately half deliver via $\mathrm{CD}$ and more than one-third of

received

June 10, 2016

accepted

June 13, 2016

published online

July 27, 2016 super obese nulliparous women undergo a scheduled primary $C D .{ }^{7,8}$ Obesity is well characterized as increasing the risk of maternal complications after $\mathrm{CD}$, including vertical hysterotomy, ${ }^{9}$ postoperative wound infections, ${ }^{10,11}$ and thromboembolism. ${ }^{12}$ Less is understood about maternal super obesity and the risk of neonatal complications during and after CD. Available literature suggests that neonates born via elective CD or failed trial of labor are more likely to experience morbidity, particularly respiratory compromise, compared to neonates born vaginally. ${ }^{13,14}$ However, little is known about whether maternal super obesity is associated with an

Copyright $\odot 2016$ by Thieme Medical Publishers, Inc., 333 Seventh Avenue, New York, NY 10001, USA. Tel: +1(212) 584-4662.
DOI http://dx.doi.org/ 10.1055/s-0036-1586122. ISSN 0735-1631. 
increased risk of neonatal morbidity, including respiratory complications, compared to nonobese women delivering via CD.

Because super obese women are at a substantially increased risk of delivering via $\mathrm{CD}$, the objective of this study was to investigate the relationship between maternal super obesity and neonatal morbidity among term infants born via CD.

\section{Materials and Methods}

This is a retrospective cohort analysis of the Eunice Kennedy Shriver National Institute of Child Health and Human Development Maternal-Fetal Medicine Unit Cesarean Registry, which was conducted from 1999 to 2002 in 19 academic centers. ${ }^{15}$ Briefly, study nurses who were blinded to delivery mode (CD or VBAC) and outcomes collected demographic data, obstetrical history, intrapartum events and neonatal outcomes for each participant. Study nurses abstracted charts for neonatal complications. For this analysis, we included women delivering nonanomalous singleton infants. We included women delivering via $\mathrm{CD}$ with and without labor as labor has been shown to decrease, but not eliminate, the risk of neonatal respiratory complications after $\mathrm{CD} .{ }^{16}$ AS the primary objective of this study was to assess the relationship between maternal obesity and neonatal morbidity after $C D$, we excluded women who delivered via VBAC. While this dataset does include women who delivered vaginally after prior $C D$, we chose not to include them in order to assess the effect of obesity on neonatal outcomes among infants delivering via the same mode of delivery. By including women only delivering via $C D$, we were able to examine if cesarean indication or operative characteristics, which differ by obesity group, influence the risk of neonatal morbidity. We also excluded women who had BMI $<18.5 \mathrm{~kg} / \mathrm{m}^{2}$, those who delivered multiple gestations, and those with infants who were stillborn, weighed $<500 \mathrm{~g}$, had gestational age $<37$ weeks, or had major congenital anomalies. We further excluded women with missing information on delivery mode, delivery BMI, and key neonatal information, including plurality, anomalies, live born status, birth weight, and gestational age at the time of birth.

Our primary exposure was maternal BMI at time of delivery categorized as 18.5 to $29.9 \mathrm{~kg} / \mathrm{m}^{2}, 30$ to $39.9 \mathrm{~kg} / \mathrm{m}^{2}, 40$ to $49.9 \mathrm{~kg} / \mathrm{m}^{2}$, and $\geq 50 \mathrm{~kg} / \mathrm{m}^{2}$. BMI was calculated by measured maternal height and weight, which were abstracted from medical charts by study nurses. We chose BMI at time of delivery and not prepregnancy BMI because it is a more reliable and complete variable and more accurately reflects gestational weight gain and maternal habitus at time of $C D$. The two primary outcomes were composite measures for acute and severe neonatal morbidity. Acute neonatal morbidity was defined as neonatal outcomes requiring treatment of the neonate in the delivery room or within 24 hours of delivery and included one of more of the following: 5-minute Apgar score $<5$, cardiopulmonary resuscitation within 24 hours of delivery, ventilator support for less than 24 hours after delivery, neonatal birth injury (brachial plexus injury, fracture, facial nerve injury, skin laceration), and transient tachypnea of the newborn (TTN). Severe neonatal morbidity was defined as severe outcomes requiring treatment after the immediate delivery period ( $>24$ hours) and included one or more of the following: grade 3 or 4 intraventricular hemorrhage, necrotizing enterocolitis, seizure, respiratory distress syndrome (RDS), hypoxic ischemic encephalopathy, meconium aspiration (MA), ventilator support for more than 2 days, sepsis, and neonatal death. We also examined arterial umbilical cord $\mathrm{pH}<7.1$ and neonatal intensive care unit (NICU) admission as secondary outcomes. As this study was conducted in 19 centers with different practices of obtaining cord blood gases at time of $\mathrm{CD}$ and NICU admission, we elected to exclude these outcomes from the composite outcome measures.

Maternal demographics, clinical and delivery characteristics, and outcomes were compared across the four BMI categories using chi-square test for trend. As our outcomes were rare ( $\leq 10 \%$ of the cohort), logistic regression models were used to estimate odds ratios and 95\% confidence intervals for the association between obesity and neonatal morbidity. Based on the literature, we selected clinically relevant and operative characteristics that are known to be associated with both maternal obesity and neonatal morbidity, including maternal age, race, gestational age, maternal diabetes, prior $\mathrm{CD}$, labor, type of anesthesia, and skin and uterine incision. Covariates were retained in the model if they were statistically significant at $p<0.05$. An interaction term was included in the model to assess the association between maternal BMI and neonatal morbidity by cesarean indication (elective repeat, emergency, indicated; a priori, $p<0.1$ was considered statistically significant). Emergency CD was defined as CD for those with nonreassuring fetal status, cord prolapse and placental abruption. Indicated $C D$ included those with contraindication to labor (e.g., history of non low-transverse incision), fetal malpresentation, suspected macrosomia, and preeclampsia.

Prior studies have associated prolonged incision-to-delivery time with both maternal obesity and neonatal morbidity at time of $\mathrm{CD} .{ }^{17,18}$ For those maternal-neonatal dyads with available information, we explored whether incision-to-delivery time (assessed as a continuous variable) or prolonged incision-to-delivery time (defined as 90th percentile or longer from incision-to-delivery in minutes) impacted the association between maternal obesity and neonatal morbidity. As with other covariates, we considered $p<0.05$ to be statistically significant.

Analyses were performed using STATA (version 13, StataCorp, College Station, TX). The University of North Carolina at Chapel Hill Institutional Review Board reviewed and deemed this study exempt.

\section{Results}

Our cohort included 41,262 maternal-neonatal dyads (-Fig. 1); $36 \%$ of women had BMI of 18.5 to $29.9 \mathrm{~kg} / \mathrm{m}^{2}, 49 \%$ had BMI of 30 to $39.9,12 \%$ had BMI of 40 to $49.9 \mathrm{~kg} / \mathrm{m}^{2}$, and $3 \%$ had BMI $\geq 50$ $\mathrm{kg} / \mathrm{m}^{2}$. With increasing severity of obesity, women were more 


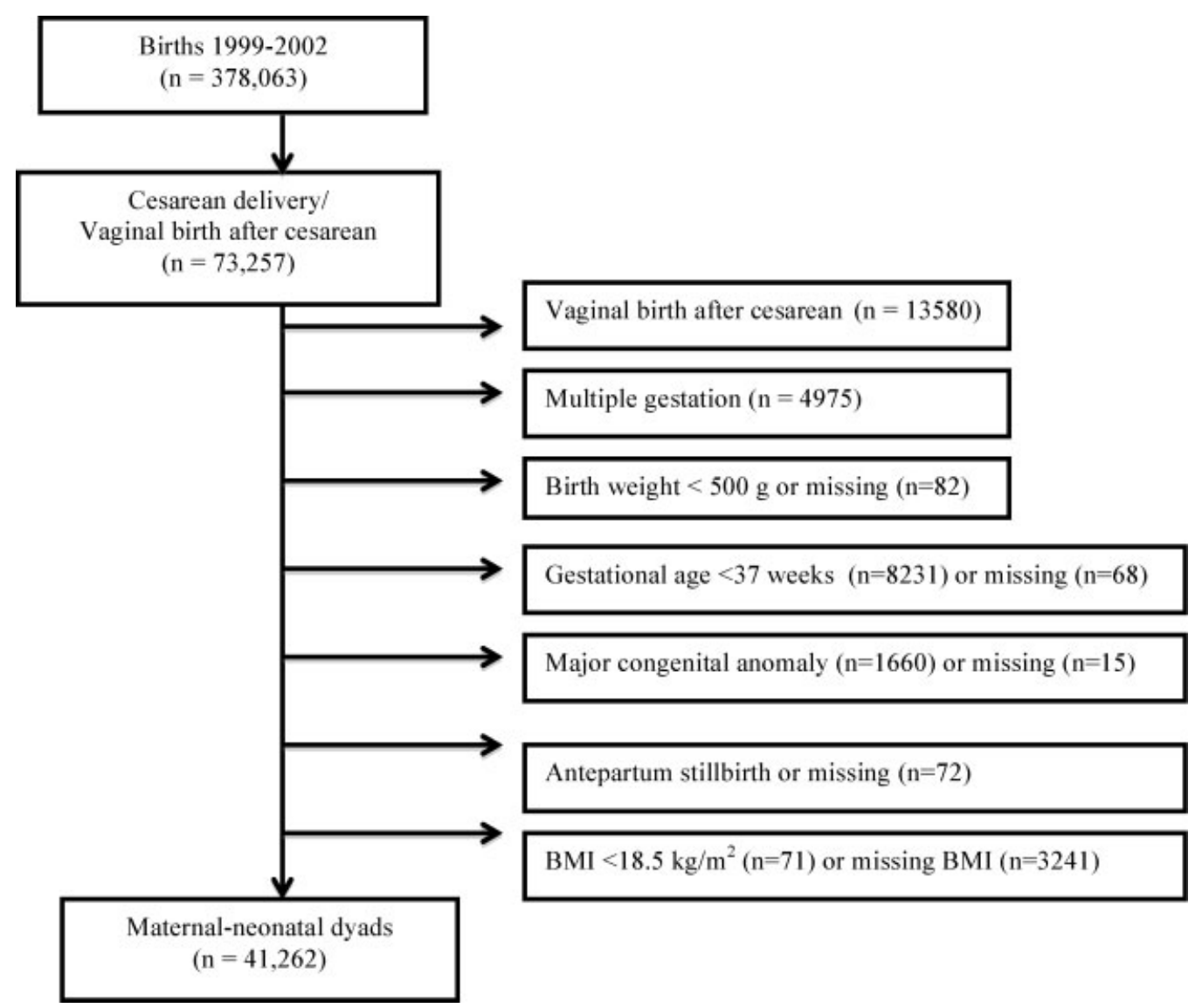

Fig. 1 Study cohort selection from Maternal-Fetal Medicine Unit Cesarean Registry (1999-2002).

likely to be Black, have pregestational diabetes and chronic hypertension, and pregnancy complications, including gestational diabetes and/or hypertensive disorders of pregnancy (gestational hypertension, preeclampsia, or eclampsia). As BMI increased, women were less likely to undergo emergency $C D$ and more likely to undergo elective $\mathrm{CD}$ ( - Table $\mathbf{1}$ ).

For the entire cohort, neonatal morbidity was uncommon: acute newborn morbidity (2.5\%), severe neonatal morbidity (3.6\%), 5-minute Apgar score $<5$ (0.4\%), and umbilical cord blood $\mathrm{pH}<7.1(6.7 \%)$, with the exception of NICU admission (13\%) (-Table 2). Acute newborn morbidity, severe neonatal morbidity, cord blood $\mathrm{pH}$, and NICU admission were most frequent among super obese women. Respiratory complications, including TTN, ventilator support, RDS, and MA, were the most common morbidities in all the obese groups and were the most frequent among super obese women. There were no statistically significant differences in neonatal mortality across BMI categories.

In multivariable models, increasing maternal BMI was associated with an increased risk of both acute and severe neonatal morbidity, after adjusting for gestational age, maternal diabetes, chorioamnionitis, general anesthesia, skin and uterine incision and CD indication ( - Table 3 ). Adjusted odds ratios were similar to unadjusted risk ratio with regard to effect magnitude. Uterine incision and labor were statistically significant only in severe neonatal morbidity models. Maternal race and prior CD were not statistically significant in either model. No statistically significant interaction was observed for $\mathrm{CD}$ indication and maternal obesity in either model (all $p>0.1$ ). For the maternal-neonatal dyads with available information ( $n=27,290)$, incision-to-delivery time was not significant in either adjusted model.

\section{Comment}

In this large study of maternal-neonatal dyads delivered via $\mathrm{CD}$, we found that maternal super obesity was associated with approximately double the risk of both acute and severe neonatal morbidity among term infants delivered via $\mathrm{CD}$. We explored neonatal outcomes requiring immediate resuscitation in the delivery room and those outcomes requiring continued treatment after delivery. Neither incision-to-delivery time as a continuous variable nor prolonged incision-to delivery time was not significant for either outcome, suggesting that maternal obesity confers the increased risk for neonatal morbidity.

Other studies have examined neonatal morbidity among obese women. Maternal obesity was associated with severe complications related to birth asphyxia, including Apgar score of 0 to 3 at 5 and 10 minutes, MA, and neonatal seizures, in a dose-dependent manner. ${ }^{19}$ Super obesity (BMI $\geq 50 \mathrm{~kg} / \mathrm{m}^{2}$ ) was associated with a fivefold risk for NICU admission compared to neonates born to non-super obese women (BMI $\left.<50 \mathrm{~kg} / \mathrm{m}^{2}\right) .{ }^{20}$ However, neither of these large Scandinavian studies included information about mode of delivery. In a 
Table 1 Maternal and delivery characteristics of women by BMI category in the MFMU Cesarean Registry $(n=41,262), 1999$ to 2002

\begin{tabular}{|c|c|c|c|c|c|}
\hline Characteristic & $\begin{array}{c}\text { BMI: } 18.5-29.9 \\
(n=14,688)\end{array}$ & $\begin{array}{l}\text { BMI: } 30-39.9 \\
(n=20,070)\end{array}$ & $\begin{array}{c}\text { BMI: } 40-49.9 \\
(n=5,195)\end{array}$ & $\begin{array}{c}\text { BMI: } \geq 50 \\
(n=1,109)\end{array}$ & $p$-Value \\
\hline Maternal age (y), median (IQR) & $29(24-33)$ & $29(24-33)$ & $28(24-33)$ & $27(23,32)$ & $<0.001$ \\
\hline Gestational age $\geq 41 \mathrm{wk}$ at delivery & $1,613(10.8)$ & $2,584(12.9)$ & $673(13.0)$ & $143(12.9)$ & $<0.001$ \\
\hline Nulliparous & $4,506(30.3)$ & $5,337(26.6)$ & $1,291(24.9)$ & $286(25.8)$ & $<0.001$ \\
\hline Black race & $2,958(18.9)$ & $5,407(26.9)$ & $2,243(43.2)$ & $656(59.2)$ & $<0.001$ \\
\hline Chronic hypertension & $92(0.6)$ & $314(1.6)$ & $227(4.3)$ & $87(7.8)$ & $<0.001$ \\
\hline Hypertensive disease of pregnancy & $743(5.0)$ & $1,843(9.2)$ & $762(14.7)$ & $205(18.5)$ & $<0.001$ \\
\hline Gestational diabetes & $584(3.9)$ & $1,573(7.8)$ & $667(12.8)$ & $159(14.3)$ & $<0.001$ \\
\hline Pregestational diabetes & $113(0.8)$ & $347(1.7)$ & $189(3.6)$ & $73(6.6)$ & $<0.001$ \\
\hline Tobacco & $1,772(11.9)$ & $2,315(11.5)$ & $793(15.3)$ & $185(16.7)$ & $<0.001$ \\
\hline Prior cesarean delivery & $8,957(60.2)$ & $12,886(64.2)$ & $3,382(65.1)$ & $705(63.6)$ & $<0.001$ \\
\hline Chorioamnionitis & $904(6.1)$ & $1,318(6.6)$ & $279(5.4)$ & $55(5.0)$ & 0.16 \\
\hline Labor & $7,358(49.4)$ & $9,370(46.7)$ & $2,392(46.0)$ & $490(44.2)$ & $<0.001$ \\
\hline Cesarean indication & & & & & $<0.001$ \\
\hline Indicated & $6,510(43.7)$ & $8,937(44.5)$ & $2,090(40.2)$ & $490(44.2)$ & \\
\hline Emergency & $2,144(14.4)$ & $2,569(12.8)$ & $694(13.4)$ & $134(12.1)$ & \\
\hline Elective repeat & $6,234(41.9)$ & $8,937(44.5)$ & $2,411(46.4)$ & $485(43.7)$ & \\
\hline Skin incision & & & & & 0.01 \\
\hline Pfannenstiel & $8,368(56.2)$ & $10,284(51.2)$ & $2,744(52.8)$ & $537(48.4)$ & \\
\hline Vertical & $1,659(11.1)$ & 2,785 (13.9) & $701(13.5)$ & $222(20.0)$ & \\
\hline Unknown & $4,861(32.7)$ & 7,001 (34.9) & $1,750(33.7)$ & $350(31.6)$ & \\
\hline Uterine incision & & & & & 0.002 \\
\hline Low transverse & $9,867(66.3)$ & $12,864(64.1)$ & $3,352(64.5)$ & $692(62.4)$ & \\
\hline Non low-transverse & $198(1.3)$ & $284(1.4)$ & $111(2.1)$ & $68(6.1)$ & \\
\hline Unknown & $4,823(32.4)$ & $6,922(34.5)$ & $1,732(33.3)$ & $349(31.5)$ & \\
\hline General anesthesia & $762(5.1)$ & $961(4.8)$ & 256 (4.9) & $71(6.4)$ & 0.82 \\
\hline Incision-to-delivery time (min), ${ }^{a}$ median (IQR) & $9(6-12)$ & $10(7-14)$ & $11(8-16)$ & $13(9-19)$ & $<0.001$ \\
\hline Incision-to-delivery time $\geq 90$ th percentile $(\mathrm{min})^{\mathrm{a}}$ & $713(7.1)$ & $1,344(10.3)$ & $572(1.6)$ & $193(25.5)$ & $<0.001$ \\
\hline
\end{tabular}

Abbreviations: BMI, body mass index; MFMU, Maternal-Fetal Medicine Unit.

${ }^{a} n=27,290$.

Note: $p$-value test for trend or Kruskal-Wallis, as appropriate. All values are $\mathrm{n}(\%)$ unless indicated as median (interquartile range).

large Swedish cohort, Blomberg found that infants delivered via $C D$ had a decreased risk of adverse neonatal outcomes compared to those delivered vaginally. ${ }^{21}$ In that cohort, the risk of adverse neonatal outcomes was the lowest among infants delivered via emergency $\mathrm{CD}$, suggesting that time to delivery may be an important component to understanding this risk. However, operative characteristics, including incision-to-delivery time, were not included in this study. In contrast to these other large studies, we were able to assess the effect of operative characteristics. By including only women delivering via $\mathrm{CD}$, we were able adjust for operative characteristics that have been shown to be associated with both maternal super obesity and neonatal morbidity, including incision-to-delivery time, type of anesthesia, and opera- tive techniques. However, we could not estimate the effect of delivery mode on this association.

Several studies have investigated neonatal outcomes among infants delivered via $C D$ and characterized operative characteristics that may contribute to this risk. In a singlecenter study ( $n=2,266)$, Conner et al found that maternal obesity was associated with both increased incision-to-delivery time and composite neonatal morbidity (5-minute Apgar score $<7$, arterial umbilical cord $\mathrm{pH}<7.1$, base excess $\leq 8$ $\mathrm{mmol} / \mathrm{L}$, and NICU or special care nursery admission). ${ }^{22}$ Our study indicates an association between maternal obesity and increased risk of neonatal morbidity among infants delivered via $\mathrm{CD}$; however, prolonged incision-to-delivery time did not alter the association between maternal obesity and neonatal 
1202 Maternal Super Obesity and Neonatal Morbidity Smid et al.

Table 2 Neonatal outcomes by maternal BMI among term singleton infants delivered via cesarean in the MFMU Cesarean Registry $(n=41,262)$

\begin{tabular}{|c|c|c|c|c|c|}
\hline Outcome & BMI: 18.5-29.9, n (\%) & BMI: 30-39.9, n (\%) & BMI: $40-49.9, \mathrm{n}(\%)$ & BMI: 50, n (\%) & $p$-Value \\
\hline $\begin{array}{l}\text { At least one acute } \\
\text { newborn morbidity }\end{array}$ & $807(5.4)$ & $1,260(6.3)$ & $441(8.5)$ & $107(9.2)$ & $<0.001$ \\
\hline 5-min Apgar score $<5$ & $49(0.3)$ & $71(0.4)$ & $26(0.5)$ & $4(0.4)$ & 0.18 \\
\hline CPR within $24 \mathrm{~h}$ of life & $41(0.3)$ & $47(0.2)$ & $13(0.3)$ & $4(0.4)$ & 0.90 \\
\hline $\begin{array}{l}\text { Ventilator support } \\
\text { within } 24 \mathrm{~h} \text { of life }\end{array}$ & $169(1.1)$ & $274(1.4)$ & $105(2.0)$ & $25(2.3)$ & $<0.001$ \\
\hline Any birth injury ${ }^{a}$ & $144(1.0)$ & $183(0.9)$ & $41(0.8)$ & $8(0.7)$ & 0.19 \\
\hline TTN & $506(3.4)$ & $835(4.2)$ & $316(6.1)$ & $77(6.9)$ & $<0.001$ \\
\hline $\begin{array}{l}\text { At least one severe } \\
\text { neonatal morbidity }\end{array}$ & $443(3.0)$ & $726(3.6)$ & $247(4.8)$ & $67(6.0)$ & $<0.001$ \\
\hline IVH grade 3 or 4 & $1(0.01)$ & $1(0.0)$ & $0(0)$ & $0(0)$ & - \\
\hline Necrotizing enterocolitis & $4(0.03)$ & $4(0.02)$ & $1(0.02)$ & $0(0)$ & - \\
\hline Seizures & $25(0.2)$ & $31(0.2)$ & $10(0.2)$ & $2(0.2)$ & 0.78 \\
\hline RDS & $306(2.1)$ & $446(2.2)$ & $157(3.0)$ & $42(3.8)$ & $<0.001$ \\
\hline HIE & $14(0.1)$ & $19(0.1)$ & $6(0.1)$ & $0(0)$ & 0.84 \\
\hline Meconium aspiration & $125(0.8)$ & $246(1.2)$ & $103(2.0)$ & $19(1.7)$ & $<0.001$ \\
\hline Ventilator support $\geq 2 \mathrm{~d}$ & $83(0.6)$ & $157(0.8)$ & $64(1.2)$ & $14(1.3)$ & $<0.001$ \\
\hline Sepsis & $45(0.3)$ & $84(0.4)$ & $32(0.6)$ & $12(1.1)$ & $<0.001$ \\
\hline Neonatal death & $6(0.04)$ & $10(0.1)$ & $4(0.1)$ & $1(0.1)$ & 0.63 \\
\hline Cord $\mathrm{pH}<7.1^{\mathrm{b}}$ & $331(6.2)$ & $529(6.3)$ & $199(9.1)$ & $56(11.0)$ & $<0.001$ \\
\hline NICU admission & $1,756(11.8)$ & $2,634(13.1)$ & $881(17.0)$ & $214(19.3)$ & $<0.001$ \\
\hline
\end{tabular}

Abbreviations: CPR, cardiopulmonary resuscitation; HIE, hypoxic ischemic encephalopathy; IVH intraventricular hemorrhage; NICU, neonatal intensive care unit; RDS, respiratory distress syndrome; TTN, transient tachypnea of the newborn.

${ }^{a}$ Birth injury includes brachial plexus or nerve injury, fracture, skin laceration, and other injuries.

${ }^{\mathrm{b}} n=16,467$.

Note: Bold denotes composite outcome. P-value test for trend.

Table 3 Logistic regression models for maternal BMI and neonatal morbidity

\begin{tabular}{|l|l|l|}
\hline \multirow{2}{*}{ Maternal and delivery characteristics } & Acute neonatal morbidity $(\boldsymbol{n}=41,262)$ & Severe neonatal morbidity $(\boldsymbol{n}=41,262)$ \\
\cline { 2 - 3 } & \multicolumn{2}{|c|}{$\begin{array}{c}\text { Adjusted OR } \\
(95 \% \text { Cl) }\end{array}$} \\
\hline BMl: $18.5-29.9 \mathrm{~kg} / \mathrm{m}^{2}$ (ref) & - & - \\
\hline BMl: $30-39.9 \mathrm{~kg} / \mathrm{m}^{2}$ & $1.19(1.01-1.41)$ & $1.26(1.11-1.42)$ \\
\hline BMl: $40-49.9 \mathrm{~kg} / \mathrm{m}^{2}$ & $1.59(1.40-1.80)$ & $1.63(1.38-1.92)$ \\
\hline BMl: $\geq 50 \mathrm{~kg} / \mathrm{m}^{2}$ & $1.81(1.46-2.25)$ & $2.08(1.59-2.73)$ \\
\hline Gestational age (ref: $39 \mathrm{wk})$ & - & - \\
\hline $37-39 \mathrm{wk}$ & $1.34(1.21-1.49)$ & $1.60(1.39-1.84)$ \\
\hline$\geq 40 \mathrm{wk}$ & $1.16(1.05-1.29)$ & $1.47(1.27-1.70)$ \\
\hline Maternal diabetes & $1.47(1.30-1.66)$ & $1.34(1.14-1.59)$ \\
\hline Chorioamnionitis & $1.79(1.56-2.06)$ & $2.19(1.79-2.58)$ \\
\hline General anesthesia & $1.74(1.51-1.99)$ & $2.12(1.79-2.51)$ \\
\hline Cesarean indication & & - \\
\hline Elective (ref) & - & $2.48(2.08-2.97)$ \\
\hline Emergency & $2.12(1.88-2.40)$ & $0.97(0.82-1.14)$ \\
\hline Indicated & $1.10(0.99-1.22)$ & \\
\hline
\end{tabular}


Table 3 (Continued)

\begin{tabular}{|l|l|l|l|}
\hline \multirow{2}{*}{ Maternal and delivery characteristics } & Acute neonatal morbidity $(\boldsymbol{n}=4 \mathbf{4 1 , 2 6 2 )}$ & Severe neonatal morbidity $(\boldsymbol{n}=4 \mathbf{2 1 , 2 6 2 )}$ \\
\cline { 2 - 3 } & \multicolumn{2}{|c|}{$\begin{array}{c}\text { Adjusted OR } \\
(95 \% \mathrm{Cl})\end{array}$} \\
\hline Skin incision & - & - \\
\hline Vertical (ref) & - & $1.36(1.16-1.59)$ \\
\hline Pfannnestiel & $1.20(1.06-1.35)$ & $0.71(0.32-1.54)$ \\
\hline Unknown & $0.78(0.68-0.90)$ & \\
\hline Uterine incision ${ }^{\text {a }}$ & & - \\
\hline Low transverse (ref) & - & $1.85(1.37-2.52)$ \\
\hline Non low-transverse & & $1.27(0.60-2.71)$ \\
\hline Unknown & & $1.26(1.10-1.47)$ \\
\hline Labor $^{\mathrm{a}}$ & - & \\
\hline
\end{tabular}

Abbreviations: BMI, body mass index; $\mathrm{Cl}$, confidence interval; OR, odds ratio; ref, reference.

aUterine incision and labor were not significant in acute morbidity model.

morbidity. From the same dataset that was used for our study, Edwards et al demonstrated that among infants delivered by prelabor CD with spinal anesthesia, a 10-point increase in maternal BMI was associated with a 0.01 -point decrease in cord blood arterial pH. Among women with BMI > 35, Pfannenstiel skin incision compared to vertical skin incision was associated with a higher frequency of umbilical cord base deficit $>12 \mathrm{mmol} / \mathrm{L}^{23}$ In a different single-center retrospective cohort study, Sutton et al demonstrated that vertical skin incision was associated with decreased neonatal morbidity (5-minute Apgar score $<7$ and cord blood $\mathrm{pH}<7.1$ ). As super obese women were more likely to undergo $C D$ with vertical skin incision, we evaluated skin incision as a potential confounder. In both the acute and severe neonatal morbidity models, Pfannenstiel skin incision was associated with an increased risk of neonatal morbidity. Our results and those from Sutton et al suggest, but do not confirm, that while Pfannenstiel skin incision may be associated with a decreased risk of maternal complications among obese women, ${ }^{10,24,25}$ this operative approach may also be associated with an increased risk of neonatal morbidity.

The primary strength of our study is the large sample size. The study sample comprises women from a variety of tertiary care centers in the United States, which makes these outcomes generalizable to many obstetrical settings with the exception of community and small hospitals. Our sample size allowed us to assess these rare neonatal outcomes among term super obese women, which would not be possible in a single-center study. We were able to examine severe neonatal outcomes rarely seen in term neonates, including meconium aspiration, RDS, need for prolonged ventilator support, and sepsis. Our study confirms that neonates born to obese women, and particularly super obese women, are at increased risk not only of adverse shortterm outcomes such as low Apgar score, but also of those adverse outcomes that require continued treatment and may be associated with long-term sequealae. ${ }^{26,27}$

Our study has limitations. This study reflects obesity rates in the United States from 1999 to 2002, when 28\% of reproductive- age women were obese compared to $32 \%$ in $2012 .{ }^{28,29}$ Additionally, further limitations include missing data, residual confounding, and the potential effect of trainees' involvement in the surgery on outcomes. Approximately one-third of women had missing data for incision-to-delivery time; thus, we were unable to assess if this interval was a significant covariate in models with our full cohort. We also do not have information about infant or childhood developmental outcomes. There may be unmeasured risk factors associated with obesity and neonatal morbidity, including maternal habitus and operative technique such as taping of the pannus during surgery. In a nationwide survey, obstetricians report that their preferred surgical approach for $C D$ among women with BMI $\geq 40 \mathrm{~kg} / \mathrm{m}^{2}$ is Pfannenstiel skin incision with taping of the pannus. ${ }^{30}$ By taping the pannus, weight may be displaced above the maternal great vessels, which may decrease placental perfusion flow and increase risk of neonatal hypoxia, leading to an increased risk of neonatal morbidity.

Our results suggest that compared to nonobese women, maternal super obesity approximately doubles the risk of neonatal morbidity among term, singleton nonanomalous neonates. Our study did not find that incision-to-delivery time significantly affects this association at the time of $\mathrm{CD}$. This information may be useful for counseling super obese women as they have an a priori risk of approximately $50 \%$ chance of delivering via CD. Our study, along with others, underscores the need to understand the mechanism of increased risk for neonatal morbidity, particularly respiratory compromise, among infants born via $\mathrm{CD}$ to super obese mothers.

Note

This paper was presented at the 2016 Society for MaternalFetal Medicine's Annual Meeting in Atlanta, GA, as two poster presentations (final abstract IDs: 221 and 650).

Conflict of Interest

None. 


\section{References}

1 Sturm R. Increases in clinically severe obesity in the United States, 1986-2000. Arch Intern Med 2003;163(18):2146-2148

2 Stotland NE, Hopkins LM, Caughey AB. Gestational weight gain, macrosomia, and risk of cesarean birth in nondiabetic nulliparas. Obstet Gynecol 2004;104(4):671-677

3 Crane JM, Murphy P, Burrage L, Hutchens D. Maternal and perinatal outcomes of extreme obesity in pregnancy. J Obstet Gynaecol Can 2013;35(7):606-611

4 Chu SY, Kim SY, Schmid CH, et al. Maternal obesity and risk of cesarean delivery: a meta-analysis. Obes Rev 2007;8(5):385-394

5 Kominiarek MA, Vanveldhuisen P, Hibbard J, et al; Consortium on Safe Labor. The maternal body mass index: a strong association with delivery route. Am J Obstet Gynecol 2010;203(3):264 e1-264.e7

6 Kominiarek MA, VanVeldhuisen P, Hibbard J, et al. The maternal body mass index: a strong association with delivery route. Am J Obstet Gynecol 2010;203:264.e1-e7

7 Marshall NE, Guild C, Cheng YW, Caughey AB, Halloran DR. Maternal superobesity and perinatal outcomes. Am J Obstet Gynecol 2012;206(5):417.e1-417.e6

8 Alanis MC, Goodnight WH, Hill EG, Robinson CJ, Villers MS, Johnson DD. Maternal super-obesity (body mass index $>$ or $=$ 50) and adverse pregnancy outcomes. Acta Obstet 2010;89(7): 924-930

9 Brocato BE, Thorpe EM Jr, Gomez LM, Wan JY, Mari G. The effect of cesarean delivery skin incision approach in morbidly obese women on the rate of classical hysterotomy. J Pregnancy 2013; 2013:890296

10 Smid MC, Kearney MS, Stamilio DM. Extreme obesity and postcesarean wound complications in the Maternal-Fetal Medicine Unit Cesarean Registry. Am J Perinatol 2015;32(14):1336-1341

11 Stamilio DM, Scifres CM. Extreme obesity and postcesarean maternal complications. Obstet Gynecol 2014;124(2 Pt 1):227-232

12 Robinson HE, O'Connell CM, Joseph KS, McLeod NL. Maternal outcomes in pregnancies complicated by obesity. Obstet Gynecol 2005;106(6):1357-1364

13 El-Sayed YY, Watkins MM, Fix M, Druzin ML, Pullen KM, Caughey AB. Perinatal outcomes after successful and failed trials of labor after cesarean delivery. Am J Obstet Gynecol 2007;196(6):583. e1-583.e5, discussion 583.e5

14 Kolås T, Saugstad OD, Daltveit AK, Nilsen ST, Øian P. Planned cesarean versus planned vaginal delivery at term: comparison of newborn infant outcomes. Am J Obstet Gynecol 2006;195(6): 1538-1543

15 Landon MB. Predicting uterine rupture in women undergoing trial of labor after prior cesarean delivery. Semin Perinatol 2010;34(4): 267-271
16 Gerten KA, Coonrod DV, Bay RC, Chambliss LR. Cesarean delivery and respiratory distress syndrome: does labor make a difference? Am J Obstet Gynecol 2005;193(3 Pt 2):1061-1064

17 Girsen AI, Osmundson SS, Naqvi M, Garabedian MJ, Lyell DJ. Body mass index and operative times at cesarean delivery. Obstet Gynecol 2014;124(4):684-689

18 Datta S, Ostheimer GW, Weiss JB, Brown WU Jr, Alper MH. Neonatal effect of prolonged anesthetic induction for cesarean section. Obstet Gynecol 1981;58(3):331-335

19 Persson M, Johansson S, Villamor E, Cnattingius S. Maternal overweight and obesity and risks of severe birth-asphyxia-related complications in term infants: a population-based cohort study in Sweden. PLoS Med 2014;11(5):e1001648

20 Bonnesen B, Secher NJ, Møller LK, Rasmussen S, Andreasen KR, Renault K. Pregnancy outcomes in a cohort of women with a preconception body mass index $>50 \mathrm{~kg} / \mathrm{m}^{2}$. Acta Obstet Gynecol Scand 2013;92(9):1111-1114

21 Blomberg M. Maternal obesity, mode of delivery, and neonatal outcome. Obstet Gynecol 2013;122(1):50-55

22 Conner SN, Tuuli MG, Longman RE, Odibo AO, Macones GA, Cahill AG. Impact of obesity on incision-to-delivery interval and neonatal outcomes at cesarean delivery. Am J Obstet Gynecol 2013;209(4): 386.e1-386.e6

23 Edwards RK, Cantu J, Cliver S, Biggio JR Jr, Owen J, Tita AT. The association of maternal obesity with fetal $\mathrm{pH}$ and base deficit at cesarean delivery. Obstet Gynecol 2013;122(2 Pt 1):262-267

24 Sutton AL, Sanders LB, Subramaniam A, Jauk VC, Edwards RK. Abdominal incision selection for cesarean delivery of women with class III obesity. Am J Perinatol 2016;33(6):547-551

25 Alanis MC, Villers MS, Law TL, Steadman EM, Robinson CJ. Complications of cesarean delivery in the massively obese parturient. Am J Obstet Gynecol 2010;203(3):271.e1-271.e7

26 Himmelmann K, Ahlin K, Jacobsson B, Cans C, Thorsen P. Risk factors for cerebral palsy in children born at term. Acta Obstet Gynecol Scand 2011;90(10):1070-1081

27 Lie KK, Grøholt E-K, Eskild A. Association of cerebral palsy with Apgar score in low and normal birthweight infants: population based cohort study. BMJ 2010;341:c4990

28 Flegal KM, Carroll MD, Kit BK, Ogden CL. Prevalence of obesity and trends in the distribution of body mass index among US adults, 1999-2010. JAMA 2012;307(5):491-497

29 Ogden CL, Carroll MD, Kit BK, Flegal KM. Prevalence of childhood and adult obesity in the United States, 2011-2012. JAMA 2014; 311(8):806-814

30 Smid MC, Smiley SG, Schulkin J, et al. The problem of the pannus: physician preference survey and a review of the literature on cesarean skin incision in morbidly obese women. Am J Perinatol 2016;33(5):463-472 